\title{
EXTRAÇÃO E CARACTERIZAÇÃO DE GELATINA A PARTIR DE SUBPRODUTOS DE TILÁPIA DO NILO (Sarotherodon niloticus)
}

\author{
M. C. M. FERREIRA ${ }^{12}$; A. F. GOMES ${ }^{2}$ e A. M. GOZZO ${ }^{2}$ \\ ${ }^{1}$ Universidade Tecnológica Federal do Paraná - Programa de Pós-Graduação em Tecnologia \\ em Alimentos \\ ${ }^{2}$ Universidade Tecnológica Federal do Paraná - Coordenação de Engenharia de Alimentos \\ E-mail para contato: angelaa@utfpr.edu.br
}

\begin{abstract}
RESUMO - A produção da gelatina a partir da pele de tilápia mostra-se uma boa alternativa na utilização destes resíduos, já que a mesma possui uma grande quantidade de colágeno em sua composição. Neste estudo foram testados quatro métodos brandos para extração de gelatina, sendo três pré-tratamentos ácidos e um neutro, avaliando características físicas como cor, composição centesimal (umidade, cinzas, proteínas e lipídeos), rendimento e força do gel. As gelatinas obtidas apresentaram baixo teor de umidade, cinzas e lipídeos. Em relação ao teor proteico, estas apresentaram teores de 77 a $81 \%$ e Bloom de médio a alto (de 184 a $267 \mathrm{~g}$ ), sendo que o produto extraído apenas em água apresentou o terceiro maior teor de proteínas e o segundo maior valor de Bloom.
\end{abstract}

\section{INTRODUÇÃO}

O setor responsável pela produção de peixes, segundo Bordignon (2010), apresentou maior crescimento em relação à produção dos demais produtos de origem animal, e o consumo de pescado aumentou em mais de $800 \%$ entre 1970 e 2006. Em 2010, a produção mundial de pescado atingiu cerca de 168 milhões de toneladas, apresentando uma expansão de 3\% em relação ao ano anterior (MPA, 2011).

A pesca é uma atividade praticada desde a antiguidade e constitui importante fonte de renda, trabalho e alimento (MPA, 2011). A tilápia-do-Nilo é uma das espécies mais cultivadas no país por possuir boa capacidade de adequação aos sistemas de produção, rápido crescimento, ser de fácil reprodução e possuir carne de sabor agradável (Boscolo et al., 2005). O problema de maior importância na cadeia produtiva da pesca é caracterizado pela alta quantidade de resíduos gerados após a filetagem, que, no caso da tilápia-do-Nilo podem chegar até $70 \%$ do peso bruto do peixe, distribuídos em cabeça, carcaça, vísceras e pele, ou seja, resíduos orgânicos com alta qualidade nutricional para obtenção de subprodutos, o que justifica o interesse na busca pelo aproveitamento destes resíduos (Bueno et al., 2011; Vidotti e Gonçalves, 2006).

Produtos como couro, hidrolisados proteicos, gelatina e colágeno são exemplos do aproveitamento dos rejeitos de pescado, reduzindo o impacto ambiental gerado pela alta carga orgânica que é depositada no ambiente se os mesmos não forem utilizados (Silva et al., 2011). A gelatina é um produto produzido a baixo custo e em grande quantidade no Brasil, e nas 
indústrias de alimentos são empregadas para melhorar características como elasticidade, estabilidade e consistência de produtos, devendo apresentar boas propriedades reológicas, principalmente a força do gel (Bloom), que determina o valor comercial da gelatina (Almeida, 2012; Cho et al., 2004).

Este estudo foi realizado com objetivo de verificar a possibilidade de extração da gelatina a partir de subprodutos de tilápia-do-Nilo, como pele e carcaça e avaliar suas características físico-químicas e de textura utilizando reagentes pouco invasivos, visando a obtenção de um produto final com baixa toxicidade.

\section{MATERIAIS E MÉTODOS}

As peles e carcaças de Tilápia-do-Nilo utilizadas nos pré-tratamentos foram doadas por um Pesqueiro, localizado na região noroeste do Paraná.

\subsection{Extração da Gelatina}

Inicialmente, as amostras foram lavadas em água corrente para eliminação de quaisquer resíduos e congeladas $\left(-18^{\circ} \mathrm{C}\right)$ até o início do processo. As extrações foram realizadas a partir de quatro métodos, todos desenvolvidos em escala piloto por Ferreira (2013), com adaptações. Ao todo foram realizados três tratamentos ácidos (gelatina tipo A) e um tratamento neutro.

O primeiro método de extração (Amostra 1) foi realizado a partir da imersão de $250 \mathrm{~g}$ de subprodutos em solução de ácido clorídrico $(\mathrm{HCl})$ a $0,3 \%$ durante 24 horas. Após este período, estes foram lavados em água corrente para retirar o excesso de ácido, adicionou-se $400 \mathrm{~mL}$ de água destilada e o $\mathrm{pH}$ foi corrigido para 6,0 com hidróxido de sódio $(\mathrm{NaOH})$. Após, a mistura foi submetida à cocção à $60^{\circ} \mathrm{C}$ por 6 horas. Por fim, os resíduos sólidos foram retirados por peneiramento e o sobrenadante resfriado em câmara fria (aproximadamente $\left.8^{\circ} \mathrm{C}\right)$.

No segundo método de extração (Amostra 2), uma massa de $250 \mathrm{~g}$ de matéria-prima foi imersa em água destilada e submetida à cocção com água a $95 \pm 2{ }^{\circ} \mathrm{C}$ por 30 minutos, seguida da separação dos sólidos por peneiramento, o sobrenadante foi armazenado à $8^{\circ} \mathrm{C}$.

O terceiro método de extração (Amostra 3) foi realizado a partir da imersão da matériaprima (250 g) em ácido acético a 4,5\% durante 4 horas. Após este pré-tratamento, as amostras foram lavadas em água corrente. Adicionou-se $400 \mathrm{~mL}$ de água destilada, submetendo o sistema à cocção a $65^{\circ} \mathrm{C}$ durante 6 horas. Os resíduos sólidos foram retirados por peneiramento e o sobrenadante armazenado a $8^{\circ} \mathrm{C}$.

No quarto método de extração (Amostra 4) se repetiu o procedimento anterior, porém, o sobrenadante foi submetido à evaporação à $90^{\circ} \mathrm{C}$ até a redução de $2 / 3$ do seu volume, com intuito de concentrar a quantidade de gelatina na amostra. Posteriormente, o sistema foi armazenado a $8^{\circ} \mathrm{C}$. 
Após a gelificação das amostras (24 horas), as mesmas foram submetidas à secagem em estufa com circulação de ar a $50^{\circ} \mathrm{C}$ por 24 a 48 horas, até que as mesmas apresentassem massa constante.

\subsection{Caracterização Físico-Química e de Textura}

O rendimento das amostras foi calculado a partir da relação entre massa da gelatina seca e o massa da matéria-prima úmida. Os teores de umidade, cinzas, conteúdo proteico total, lipídeos, cor e pH foram determinados de acordo com o Instituto Adolfo Lutz (2008). A determinação da força do gel (Bloom) foi realizada após a reidratação das gelatinas, a partir da metodologia descrita por Bueno (2008).

\section{Resultados e Discussão}

Recentemente, a aplicação de gelatina de peixe em substituição às fontes de mamíferos tem atraído especial atenção, no entanto, conhecer as propriedades físico-químicas é de fundamental importância para direcionar sua aplicação (Sow e Yang, 2015). A Tabela 1 apresenta as características físico-químicas e de textura das quatro extrações analisadas.

Tabela1: Propriedades físico-químicas e de textura das quatro extrações.

\begin{tabular}{|c|c|c|c|c|}
\hline Característica & Amostra 1 & Amostra 2 & Amostra 3 & Amostra 4 \\
\hline Rendimento (\%) & 10,38 & 6,21 & 9,37 & 12,08 \\
\hline Umidade (\%) & $9,54^{\mathrm{a}}$ & $5,34^{\mathrm{c}}$ & $7,54^{\mathrm{b}}$ & $7,19^{b}$ \\
\hline Cinzas $(\%)$ & $5,65^{\mathrm{a}}$ & $1,8^{\mathrm{d}}$ & $3,92^{b}$ & $3,31^{\mathrm{c}}$ \\
\hline Proteínas (\%) & $77,91^{\mathrm{a}}$ & $80,22^{\mathrm{a}}$ & $81,56^{\mathrm{a}}$ & $80,63^{\mathrm{a}}$ \\
\hline Lipídeos (\%) & $0,43^{\mathrm{a}}$ & $3,79^{b}$ & $0,35^{\mathrm{a}}$ & $0,25^{\mathrm{a}}$ \\
\hline Força do gel (g) & $267^{\mathrm{a}}$ & $240^{\mathrm{b}}$ & $184^{\mathrm{c}}$ & $205^{\mathrm{d}}$ \\
\hline
\end{tabular}

O rendimento da extração de gelatina ficou entre 6,21 e 12,08\% (gramas de gelatina seca por $100 \mathrm{~g}$ de pele úmida). Os resultados foram semelhantes aos encontrados por Trindade (2010) com rendimentos entre 5,91\% e 10,95\%, inferiores aos 18,3\% obtidos por Bueno et al. (2011) e superiores ao de 5,10\% obtidos por Alfaro (2008). O rendimento da gelatina extraída da pele de tilápia geralmente é superior ao de outros peixes, a extração depende dos componentes solúveis presentes nas peles, de sua composição centesimal e da quantidade de colágeno, além do método de extração empregado e da idade do peixe utilizado (Trindade, 2010). Neste estudo, o melhor rendimento foi obtido pela extração 4, o que já era esperado pois o sobrenadante passou pelo processo de evaporação antes da secagem, otimizando o processo. Esta análise comprova que pode-se, no método testado, manter o colágeno por um maior tempo em alta temperatura sem desnaturá-lo. O processo 2 apresentou o menor rendimento, no entanto, foi utilizado apenas água na extração, o que promove uma menor quantidade de resíduos no produto final. Mesmo sendo o menor valor encontrado neste trabalho, esta extração apresentou valor superior a muitos pesquisadores (Ferreira, 2013; Bueno et al. 2011; Alfaro, 2008 e Silva et al., 2011). 
Os métodos de extração testados não apresentaram eficiência em relação à produção de gelatina a partir das carcaças de tilápia, já que não houve gelificação das amostras. Silva et al. (2011) obtiveram baixo rendimento (1,5 a 2,3\%) ao utilizar cabeças e carcaças de carpa como matéria-prima para extração de colágeno. Galan (2010) utilizou carcaças de tilápia na produção de gelatina e farinha de peixe, obtendo um alto teor protéico somente para a farinha, o autor destaca que somente a pele de tilápia fornece bons resultados para a produção de gelatina, representando uma excelente forma de aproveitamento destes subprodutos.

O percentual de umidade das amostras (Tabela1) ficou entre 5,34\% e 9,54\%. De acordo com o teste de Tukey com 95\% de confiança, as amostras 1,2 e 3 diferiram significativamente entre si e as amostras 3 e 4 são significativamente iguais. Segundo Bordignon (2010), essas diferenças podem ocorrer em função dos diferentes métodos de lavagem e conservação das peles antes do início do processo de extração e principalmente em relação ao tempo de secagem das gelatinas após o processo.

A análise de cinzas foi realizada para determinar a quantidade de matéria inorgânica presente nas amostras. Os resultados diferiram entre si (Tabela 1) em relação a esta análise, variando entre 1,8 e 5,65\%. Bueno et al. (2011) analisaram a quantidade de cinzas presente em gelatinas comercial e provenientes de peles de tilápia, o teor de cinzas da amostra comercial manteve-se em torno de $0,3 \%$, e as derivadas de peixe ao redor de $1,8 \%$, valores bastante inferiores às amostras 1,3 e 4 deste trabalho. Isto se deve provavelmente a filtração inadequada do sobrenadante antes de realizar a secagem, evidenciando a necessidade de adequar esta operação unitária nos processos estudados. Pesquisas com peles de peixe realizadas por Bordignon (2010), Jongjareonrak et al. (2010) e Alfaro (2008) apresentaram teores de cinzas de $2,37 \%, 0,33 \%$ e $2,51 \%$, respectivamente, valores inferiores ao verificados neste estudo. De acordo com Jones (1977) o teor máximo de cinzas recomendado para gelatinas é de $2,6 \%$, apesar de usualmente gelatinas com conteúdo acima de $2 \%$ sejam aceitas para aplicações alimentícias (CHO et al., 2004).

A gelatina possui em sua composição grande quantidade de proteínas, pois é resultado da hidrólise parcial do colágeno animal. As amostras obtidas neste estudo (Tabela 1) forneceram teores de proteínas entre 77 e $81 \%$, não apresentando diferença significativa entre os pré-tratamentos (intervalo $95 \%$ de confiança). É importante ressaltar que a gelatina extraída apenas em água apresentou um alto teor de proteínas $(80,22 \%)$, não diferindo significativamente das demais. O mesmo não ocorre com as demais origens proteicas, evidenciando, assim, a importância do estudo do pescado na produção de colágeno (Ferreira, 2013). Estudos realizados com subprodutos de peixe, desenvolvidos por Alfaro (2008) e Bordignon (2010) apresentaram gelatinas com $81,16 \%$ e $85 \%$ de proteínas, respectivamente, resultados semelhantes aos verificados neste estudo. Estes valores foram inferiores aos encontrados por Songchotikupan et al. (2008) e Bueno et al. (2011), que obtiveram gelatina de peles de tilápia com $89,40 \%$ e $88,90 \%$ de proteínas em sua composição. Vários estudos demostram que fontes alternativas podem ser utilizadas em substituição à extração de colágeno de derivados de mamíferos. Estudos realizados a partir da extração proteica de subprodutos de frango resultaram em $78,52 \%$ de proteínas provenientes de tarsos (Almeida, 2012) e, gelatinas obtidas a partir de pés de frango utilizando pré-tratamentos semelhantes aos utilizados neste estudo apresentaram de 67,5 a 69,9\% de proteínas (Ferreira, 2013). 
Os resultados da quantidade de lipídeos (Tabela 1) presente nos sistemas avaliados apresentaram-se razoavelmente baixos nas amostras 1,3 e $4(0,43,0,35$ e $0,25 \%$, respectivamente). A gelatina obtida apenas a partir de água (amostra 2) apresentou maior conteúdo de extrato etéreo (3,79\%), provavelmente a ausência de componentes, ácidos ou básicos, não tenha permitido a hidrólise dos lipídeos, dificultando a sua retirada. Neste processo, um critério maior na extração da gordura do sobrenadante deve ser considerado. Almeida (2012) obteve, a partir de gelatinas extraídas de tarsos de frango cerca de 9,919\% de gordura, percentual muito elevado em relação aos resultados obtidos neste estudo. No caso de gelatina a partir da pele de tilápia, teores extremamente baixos de extrato etéreo foram encontrados por Bordignon (2010), os quais ficaram em torno de $0,025 \%$ e $0,047 \%$. Alfaro (2008) obteve teor de $0,25 \%$ de gordura em amostras de gelatina a partir da pele de tilápia. O autor também destaca que banhos sucessivos anteriores às extrações são eficientes na remoção do conteúdo lipídico das peles de tilápia, o que também pode justificar a alta quantidade de gordura na amostra 2 em relação as demais, já que a mesma foi lavada apenas em água corrente antes da extração em alta temperatura, enquanto que as outras foram lavadas antes e após o pré-tratamento, aumentando a remoção lipídica.

Os valores de força do gel foram de $267 \mathrm{~g}, 240 \mathrm{~g}, 184 \mathrm{~g}$ e $205 \mathrm{~g}$, respectivamente, nas amostras de 1 a 4 (Tabela 1). Os resultados obtidos neste estudo mostram que foram obtidas duas amostras ( 1 e 2 ) com valor de alto Bloom e duas ( 3 e 4) com médio Bloom. Por formar géis estruturalmente fracos e fortes (auto-sustentáveis), conclui-se que as gelatinas obtidas de subprodutos de tilápia podem ser utilizadas em diversas aplicações, conforme a necessidade da indústria. De acordo com Bordignon (2010), o Bloom é uma das mais importantes propriedades funcionais da gelatina e está diretamente ligada à sua resistência a degradação. A força gel é afetada pelas condições de maturação, temperatura e tempo de estocagem, $\mathrm{pH}$, matéria prima e processo. Vale salientar que a gelatina extraída apenas em água apresentou o segundo maior valor de Bloom, o que é muito satisfatório já que não foram utilizados compostos ácidos e alcalinos como pré-tratamento.

Os géis obtidos apresentaram-se bastante firmes, lisos e com o mínimo de gordura superficial. O hidrogel que apresentou maior diferença entre as demais foi a extraída apenas em água (extração 2), com aparência escura e opaca comparando-se às amostras 1, 3 e 4 que apresentaram-se bastante translúcidas e brilhosas. O mesmo resultado foi observado nas amostras secas, onde todas apresentaram uma coloração amarelo claro, exceto a extração 2 , com tonalidade marrom.

Assim, de acordo com as características físico-químicas e reológicas apresentadas pelas gelatinas extraídas, destaca-se a extraída apenas em água (amostra 2), pois apresentou alto teor de proteínas e alta força de gel (Bloom) em sua composição, sendo o método mais econômico, menos invasivo e com baixa toxicidade proveniente de reagentes químicos.

\section{Conclusão}

Com base nos resultados obtidos, conclui-se que o aproveitamento da pele de tilápiado-Nilo em conjunto com reagentes pouco invasivos na produção de gelatina mostra-se uma boa alternativa ao setor produtor de pescado, já que as mesmas apresentaram características satisfatórias. A alta quantidade de proteínas encontrada nas gelatinas obtidas neste estudo e os 
bons valores de Bloom demonstra a importância na busca de fontes alternativas que substituam a extração com derivados de mamíferos.

Por outro lado, o uso das carcaças de tilápia para produção de gelatina não é recomendado, mas sim, para a produção de produtos como a farinha de peixe.

\section{Referências Bibliográficas}

ALFARO, A. T. Otimização das condições de extração e caracterização da gelatina de pele de tilápia (Oreochomis urolepis hornorum). Tese de Doutorado (Programa de Pós-Graduação em Ciência e Tecnologia Agroindustrial). Universidade Federal de Pelotas, 2008.

ALMEIDA, P. F. Análise da qualidade de gelatina obtida de tarsos de frango e aspectos envolvidos no processo produtivo. Dissertação de Mestrado (Programa de Pós-Graduação em Engenharia de Produção). Universidade Nove de Julho, 2012.

BORDIGNON, A. C. Caracterização da pele e da gelatina extraída de peles congeladas e salgadas de tilápia do Nilo (Oreochromis niloticus). Dissertação de Mestrado (Programa de PósGraduação em Zootecnia). Centro de Ciências Agrárias, Universidade Estadual de Maringá, 2010.

BOSCOLO, W.R.; HAYASCHI, C.; MEURER, F. et al. Farinha de resíduos da filetagem de tilápia na alimentação de tilápia do Nilo (Oreochromis niloticus) na fase de reversão sexual. Revista Brasileira de Zootecnia, v.34, n.6, p.1807-1812, 2005.

BUENO, C. M. M. Extração e caracterização de gelatina de pele de tilápia e aplicação como agente encapsulante de óleo de salmão em micropartículas obtidas por coacervação complexa. Dissertação (Mestre em Alimentos e Nutrição) - Faculdade de Engenharia de Alimentos, Universidade Estadual de Campinas, Campinas, 2008.

BUENO, C. M.; AlviM, I. D.; KOBERSTEIN, T. C. R. D.; PORTEllA, M. C.; GROSSO, C. Produção de gelatina de pele de tilápia e sua utilização para obtenção de micropartículas contendo óleo de salmão. Brazilian J of Food Technol, Campinas, v. 14, n. 1, p. 65-73, 2011.

CHO, S. M.; KWAK, K. S.; PARK, D. C.; GU, Y. S.; JI, C. I.; JANG, D. H.; LEE, Y. B.; KIM, S. B. Processing optimization and functional properties of gelatin from shark (Isurus oxyinchus) cartilage. Food Hydrocolloids, v. 18, p. 573-579, 2004.

GALAN, L. G. Farinha de Carcaça de Tilápia do Nilo (Oreochromis Niloticus) em Dietas para Coelhos: Desempenho, Perfil Lipídico, Composição Química e Resistência Óssea. Tese (Mestrado em Zootecnia) Programa de Pós-Graduação em Zootecnia, Universidade Estadual de Maringá, Maringá, 2010.

INSTITUTO ADOLFO LUTZ. Normas Analíticas do Instituto Adolfo Lutz. Métodos físico-químicos para análise de alimentos, $4^{\mathrm{a} E d}$. São Paulo: IMESP, 2008.

FERREIRA, M. F. Extração e caracterização de gelatina proveniente de subprodutos do frango: pés. 2013. 48f. Trabalho de Conclusão de Curso (Engenharia de Alimentos), Universidade Tecnológica Federal do Paraná, Campo Mourão, 2013.

JONES, N. R. Uses of gelatin in edible products. In: WARD, A. G.; COURTS, A. The sci and technol of gelatin. London: Academic Press, p. 365-394, 1977.

JONGJAREONRAK, A.; RAWDKUEN, S.; CHAJIAN, M.; BENJAKUL, S.; OSAKO, K.; TANAKA, M. Chemical compositions and characterization of skin gelatin from farmed giant catfish (Pangasianodon gigas). Food Sci and Technol, v. 43, p.161-165, 2010.

MPA. Boletim Estatístico da Pesca e Aquicultura. Ministério da Pesca e Aquicultura, 2011.

SILVA, R. S. G.; BANDEIRA, S. F.; PETRY, F. C.; PINTO, L. A. A. Extração de gelatina a partir das peles de cabeças de carpa comum. Ciência Rural, v. 41, n. 5, p. 904-909, 2011.

SHONGCHOTIKUNPAN, P.; TATTIYAKUL, J. SUPAPHOL, P. Extraction and electrospinning of gelatin from fish skin. Int $J$ of Biol Macromolecules. v.42, p.247-255, 2008. 
SOW, L. C.; YANG, H. Effects of salt and sugar addition on the physicochemical properties. Food Hydrocolloids. v. 45, p. 72-82, 2015.

TRINDADE, F. Desenvolvimento de biofilmes de gelatina de pele de pescado e aplicação para conservação de frutas. Relatório Final de Atividades (Programa Institucional de Iniciação Científica). Universidade Tecnológica Federal do Paraná - Campus Francisco Beltrão, 2010.

VIDOTTI, R. M.; GONÇALVES, G. S. Produção e caracterização de silagem, farinha e óleo de tilápia e sua utilização na alimentação animal. Instituto de Pesca, São José do Rio Preto, 2006. 